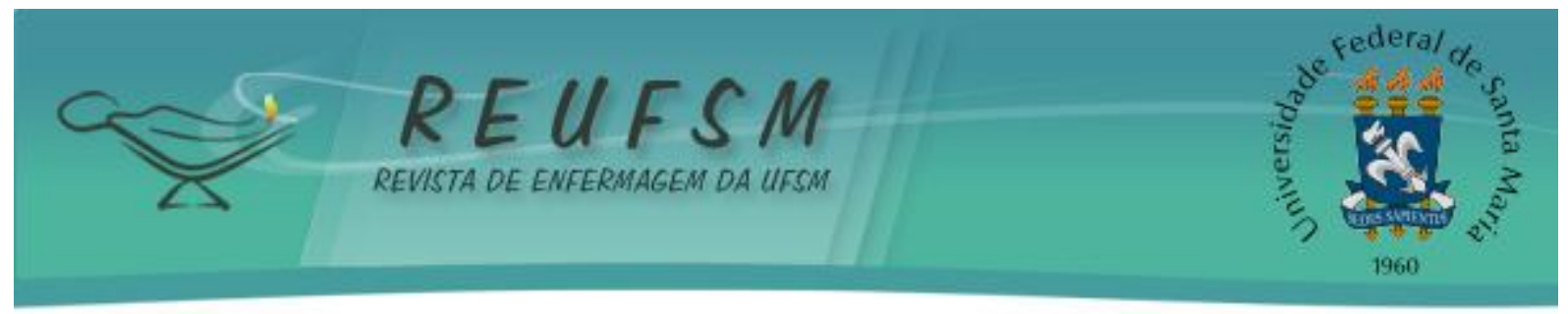

ARTIGO ORIGINAL

\title{
DESGASTE NO SERVIÇO DE ATENDIMENTO PRÉ-HOSPITALAR MÓVEL: PERCEPÇÃO DOS ENFERMEIROS
}

\section{BURNOUT IN THE SERVICE MOBILE PRE-HOSPITAL: PERCEPTION OF NURSES \\ EL DESGASTE EN EL SERVICIO DE ATENCIÓN PRE-HOSPITALARIA MÓVIL: PERCEPCIÓN DE LOS ENFERMEROS}

Cláudia Cristiane Filgueira Martins ${ }^{1}$ Andrezza Graziela Veríssimo Pontes ${ }^{2}$ Alcivan Nunes Vieira ${ }^{3}$ Viviane Euzébia Pereira Santos ${ }^{4}$

RESUMO: Objetivo: descrever como os enfermeiros do atendimento pré-hospitalar percebem o desgaste relacionado ao trabalho. Método: estudo descritivo de abordagem qualitativa, realizado por meio de entrevistas com sete enfermeiros do serviço de atendimento móvel as urgências (SAMU) em Mossoró, Brasil. O período de coleta de dados foi de março a abril de 2010 e os dados foram analisados à luz da Análise do Discurso (AD). Resultados: após o tratamento dos dados emergiram três núcleos de sentido: desgaste relacionado com as particularidades do pré-hospitalar; desgaste e as condições do serviço e o desgaste relacionado ao corpo físico e a mente. Conclusões: com a concretização desse estudo percebemos que os enfermeiros compreendem que o desgaste relacionado ao trabalho é agravado devido às condições de trabalho e pela jornada de trabalho desses profissionais.

Descritores: Enfermagem; Saúde do trabalhador; Unidades móveis de saúde.

ABSTRACT: Objective: to describe how nurses in pre-hospital care perceived work-related burnout. Method: qualitative descriptive study, conducted through interviews with seven nurses of the emergency mobile service (SAMU) Mossoró, Brazil. The data collection period was from March to April 2010 and data were analyzed in the light of discourse analysis (DA). Results: the data were treated in the light of discourse analysis (DA) and classified in three clusters of meaning: wear related to the peculiarities of the pre-hospital care; wear and conditions of service and wear related to the physical body and mind. Conclusions: with the completion of this study perceive that nurses understand that work-related wear is exacerbated by working conditions and working hours of these professionals.

Descriptors: Nursing; Occupational health; Mobile health units.

RESUMEN: Objetivo: describir cómo los enfermeros en la atención prehospitalaria percibían el desgaste relacionado al trabajo. Método: estudio descriptivo de abordaje cualitativo, realizado a través de entrevistas con siete enfermeros del servicio de atención móvil de emergencia (SAMU) MOSSORÓ, Brasil. El período de recolección de

\footnotetext{
${ }^{1}$ Enfermeira. Mestranda do Programa de Pós-Graduação em Enfermagem da UFRN. Membro do Laboratório de Membro do grupo laboratório de investigação do cuidado, segurança e tecnologias em saúde e enfermagem da Universidade Federal do Rio Grande do Norte. Bolsista Capes. E-mail: claudiacrisfm@yahoo.com.br

${ }^{2}$ Enfermeira. Mestre em Saúde Pública-UFC. Professora da Faculdade de Enfermagem da Universidade do Estado do Rio Grande do Norte-UERN. E-mail: andrezzagazi@hotmail.com

${ }^{3}$ Enfermeiro. Mestre em Cuidados Clínicos em Saúde UECE. Professor Assistente I da Faculdade de Enfermagem da UERN. E-mail: alcivan_nunes@yahoo.com.br

${ }^{4}$ Enfermeira. Doutora em Enfermagem. Professora Permanente do Departamento de Enfermagem e Pós Graduação em Enfermagem e membro do grupo laboratório de investigação do cuidado, segurança e tecnologias em saúde e enfermagem da Universidade Federal do Rio Grande do Norte. E-mail: vivianeepsantos@gmail.com
} 


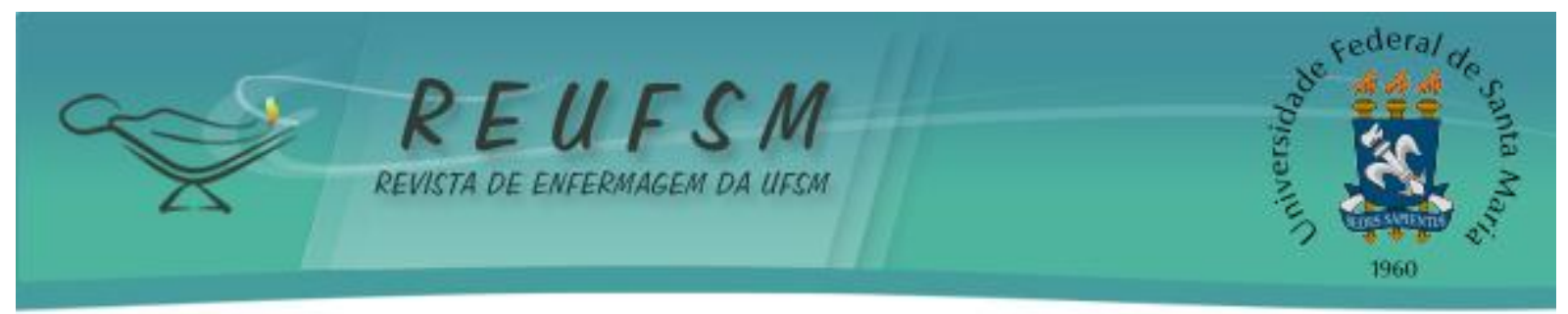

datos fue entre marzo y abril de 2010 y los datos fueron analizados a la luz del análisis del discurso (AD). Resultados: después del tratamiento de los datos se clasificaran tres grupos de significado: desgaste relacionado con las peculiaridades de la atención prehospitalaria, el desgaste y las condiciones de servicio y el desgaste relacionado con el cuerpo físico y la mente. Conclusiones: con la finalización de este estudio percibimos que los enfermeros entienden que el desgaste relacionado al trabajo se agrava por las condiciones de trabajo y las horas de trabajo de estos profesionales.

Descriptores: Enfermería; Salud laboral; Unidades móvieles de salud.

\section{INTRODUÇÃO}

O desgaste físico e mental relacionado ao trabalho dos enfermeiros que atuam no ambiente pré-hospitalar é a temática central deste estudo. 0 estudo sobre o desgaste e a forma como ele é visualizado no serviço de saúde por seus trabalhadores, se justifica por ser uma importante fonte para refletir o trabalho em saúde. Ao identificarem, descreverem e conceituarem estas questões estes atores podem compreender de que forma a realidade vivenciada é capaz de afetar sua qualidade de vida. Proporcionando um maior aprofundamento sobre o conhecimento do processo saúde/doença e ambiente de trabalho.

Nesta pesquisa, adotou-se o aporte teórico-conceitual da saúde do trabalhador. Refletiu-se sobre o processo de trabalho, o grau de desenvolvimento das forças produtivas e relações sociais de produção. ${ }^{1}$

Nesse sentido, a categoria "processo de trabalho" é central. Assim, se faz pertinente discutir a produção dos serviços de saúde e o processo de trabalho da enfermagem, no atendimento pré-hospitalar móvel (APHM).

Quanto à produção dos serviços de saúde, é preciso considerar alguns aspectos fundamentais. Primeiramente, é que ela constitui um processo inserido num campo geral de trabalho, no qual compartilha características comuns a outros setores como a instabilidade, precarização do trabalho, ritmo intenso e jornadas de trabalho prolongadas, redução da remuneração e perda do controle de sua atividade. ${ }^{2}$

Outro ponto que merece destaque é o fato da especificidade desse serviço, sendo - estabelecimento de laços com os usuários e relações interpessoais muito intensas, fatores decisivos para a própria eficácia do trabalho. ${ }^{3}$

A enfermagem, integrante do processo de produção dos serviços de saúde, se encontra a mercê das determinações sociais a que qualquer serviço de saúde impõe na sociedade atual. Submetendo-se também às relações de produção que se estabelecem no setor saúde.

Dentro da produção de serviços de saúde, encontra-se o trabalho de APHM que tem o propósito de realizar o atendimento fora do ambiente hospitalar. Buscando oferecer uma resposta imediata ao agravo de saúde que a vítima está sofrendo. ${ }^{4}$

Os profissionais do APHM trabalham com situações de urgência e emergência, onde o risco iminente de vida é uma constante. O trabalho nessa unidade exige dos profissionais conhecimentos, qualificação e rapidez para a tomada de decisões.

$O$ processo de trabalho do enfermeiro em APHM consiste em: supervisão da equipe de enfermagem, executar as prescrições médicas, assistir os pacientes graves que exigem procedimentos complexos, tomar decisões imediatas; fazer controle de qualidade no serviço. ${ }^{4}$

Dessa forma, o enfermeiro que trabalha em unidade de APH fica submetido a uma rotina que exige atenção constante; contato com situações onde o limiar entre a vida e a morte está presente; além de situações de urgências e emergências em que passa a exigir do profissional um maior autocontrole de suas ações, e o pensamento rápido no momento do atendimento.

Acarretando, assim, a esse profissional um quadro de estresse crônico que pode desencadear um processo de desgaste desse trabalhador. Este já é reconhecido como uma 


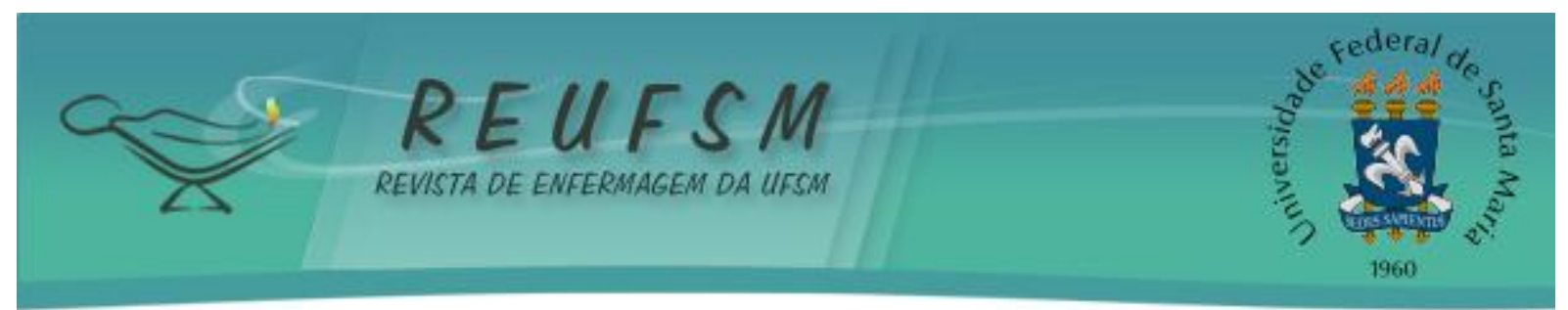

doença relacionada ao trabalho sendo conceituada como a perda de energia, fadiga do indivíduo a qual pode manifestar-se fisicamente, psiquicamente ou como uma combinação dos dois. ${ }^{4-5}$

0 desgaste dos trabalhadores de determinado grupo social é decorrente das cargas de trabalho presentes no seu processo de trabalho, e da interação entre as mesmas que potencializa o desgaste. Decorre também da relação dessas cargas com o eixo biopsíquico humano. Trata-se, portanto, de consequência dessa relação no processo psíquico e biológico de determinada coletividade, apresentada em contexto histórico específico. ${ }^{5}$

A questão norteadora dessa pesquisa é: qual a percepção dos enfermeiros que atuam no atendimento pré-hospitalar acerca do desgaste no trabalho? Frente a isso, este estudo teve como objetivo descrever como os enfermeiros de atendimento pré-hospitalar percebem o desgaste relacionado ao trabalho.

\section{MÉTODO}

Trata-se de uma pesquisa qualitativa do tipo descritiva. 0 local do estudo foi o serviço de atendimento móvel de urgência (SAMU) da cidade de Mossoró, Rio Grande do Norte, Brasil. 0 público alvo foram os enfermeiros que atuavam nesse serviço, que compreende um universo de oito profissionais. Desses sete aceitaram participar da pesquisa e contemplaram os critérios de inclusão: trabalhar no SAMU - Mossoró há mais de seis meses, ter disponibilidade em participar da pesquisa fora do expediente no SAMU e concordar em assinar o termo de consentimento livre e esclarecido (TCLE).

Como instrumento de coleta de dados utilizou-se a entrevista semiestrutura, onde foi questionado sobre o tempo de formação, quantidade de vínculos empregatícios, bem como três questionamentos quanto ao que esses profissionais entendiam e visualizavam como desgaste no seu ambiente de trabalho. A aplicação desse instrumento se realizou no período de março a abril de 2010 na rede SAMU em Mossoró-RN.

Após essa etapa, como forma de codificar os entrevistados, esses foram denominados no estudo por ordem cronológica de período de realização das entrevistas e identificados pela letra $\mathrm{E}$, representando a palavra Enfermeiro seguido de um número de ordem de sua entrevista, assim ficou E1, E2, E3, E4, E5, E6 e E7.

0 tratamento dos dados ocorreu a partir do método da Análise do Discurso (AD). ${ }^{6}$ Trata-se de um procedimento que se propõe a articular três regiões do conhecimento: o materialismo histórico, a linguística e a teoria do discurso, possibilitando uma reflexão sobre os contextos e as condições em que os discursos são produzidos e apreendidos. ${ }^{7}$

Os dados foram transcritos adotando o procedimento da $A D$ pudemos realizar a análise em quatro momentos distintos, sendo esses: Estudo das palavras do texto, análise da construção de frases, construção da rede semântica e por fim a análise. ${ }^{7}$

Após esse momento e a partir da fala dos entrevistados permitiu a elaboração de três núcleos de sentido, sendo estes: desgaste relacionado às particularidades do pré-hospitalar; desgaste relacionado às condições de serviço; desgaste do corpo físico e da mente.

A pesquisa foi submetida à apreciação do Comitê de Ética e Pesquisa da Universidade Estadual do Rio Grande do Norte (CEP/UERN) obtendo aprovação sob o protocolo $51 / 09$.

\section{RESULTADOS E DISCUSSÃO}

Com a análise dos dados pode-se traçar o seguinte perfil dos entrevistados: todos sete atores da pesquisa possuíam mais de quinze anos de formação; cindo eram do sexo feminino, três possuíam dois vínculos empregatícios, um possuía três e apenas um trabalhava somente no SAMU, e uma média de idade de trinta e três anos. 


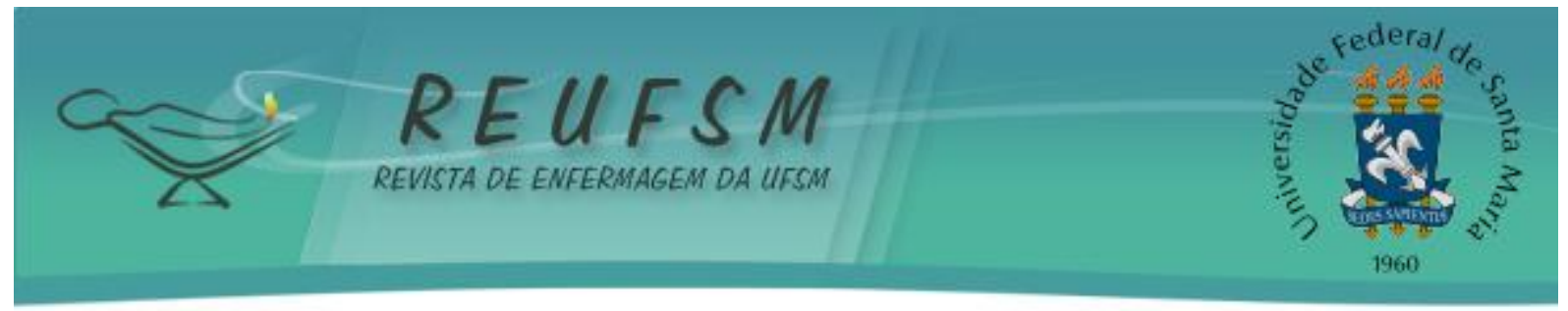

Desgaste relacionado às particularidades do pré-hospitalar

Neste núcleo de sentido, os sujeitos relacionaram o desgaste à própria constituição do APHM e à dinâmica do trabalho, que é realizado em condições adversas que implicam em risco de vida para os trabalhadores:

O APH é [...] desgastante não sei se é bem desgastante, mas o risco de vida do profissional é eminente. (E3)

Assim, o profissional enfermeiro, ao prestar o atendimento no pré-hospitalar, convive constantemente com cenas de violência, de morte, de tumulto dos transeuntes em via pública, de familiares ansiosos, cenas onde a dor da perda de entes queridos contagia os próprios trabalhadores. Pois, nestas situações, o acesso à rede assistencial dá-se prioritariamente por meio do SAMU, já que é considerado uma das portas de entrada do Sistema Único de Saúde (SUS). O que pode ser visualizado nas falas dos entrevistados:

Ah! Eu terminei o atendimento, eu esqueço, tem coisas que você não esquece [...] isso de alguma forma interfere e a gente leva para dia a dia mesmo, leva para casa. (E3)

Às vezes também certas violências que a gente vê dá muito desgaste [...] às vezes as pessoas se acumulam, não entendem o que a gente está fazendo. (E6)

Percebe-se, então, a presença das cargas psíquicas que estão constituídas por aqueles elementos do processo de trabalho que são acima de tudo fonte de estresse e que se relacionam com todos os elementos do processo de trabalho e, portanto, com as demais cargas de trabalho. ${ }^{3}$ Entre os elementos que constituem as cargas psíquicas segundo os enfermeiros de pré-hospitalar, cabe destacar: o ritmo e a intensidade do trabalho; a atenção, a responsabilidade, o grau de controle e iniciativa na execução da assistência; a intercomunicação dos trabalhadores durante a jornada, o caráter de supervisão e a consciência do risco que a tarefa implica.

Estas questões colocam o profissional em uma situação de extremo estresse, podendo ser traduzido como sentimentos de temor e ansiedade:

Eu acho que o serviço de urgência e emergência tem essa característica inerente de você se deparar sempre com situações que lhe desgastam emocionalmente. (E2)

Infere-se aqui que há uma naturalização das cargas psíquicas desse ambiente de trabalho. Conforme os entrevistados o desgaste desse profissional é inerente ao cuidado prestado ao ambiente de pré-hospitalar.

\section{Desgaste relacionado às condições de serviço}

Sobre as condições de trabalho alguns autores ${ }^{5,7-8}$ relatam que estas incorporam aspectos específicos do ambiente, mas também a organização técnica, o domínio do saber, o cenário e o próprio ambiente no qual se efetua o trabalho. 


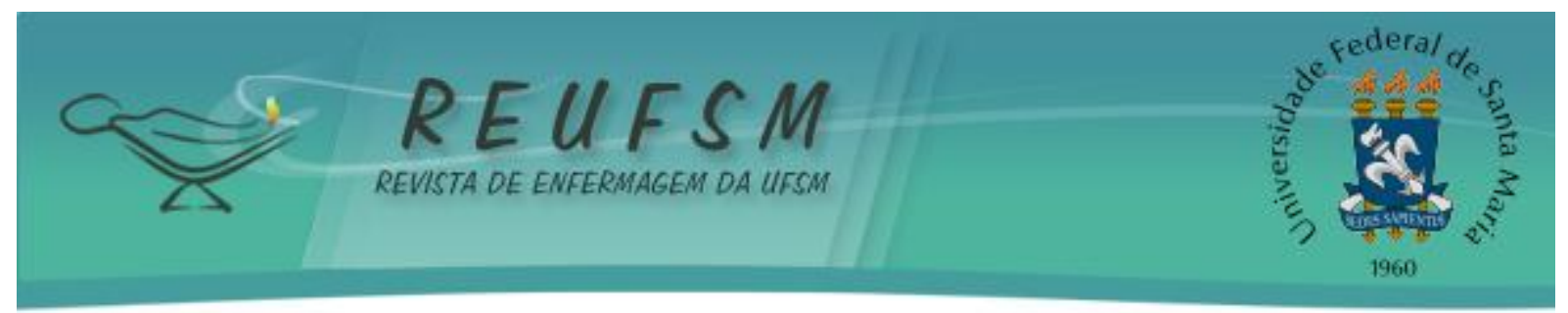

A percepção desses trabalhadores sobre as condições de trabalho se remete ao fato de ter que lidar com situações de urgência e ao mesmo tempo se sentirem impotentes devido a gravidade dos pacientes e as condições em que o trabalho foi realizado.

A gente fica assim um pouco deprimido, quando a gente se coloca no lugar do paciente [...] a gente não queria ter recebido o atendimento que recebeu, quando a gente poderia ter dado um atendimento bem melhor, se sentindo impotente. (E1)

Os profissionais de enfermagem que trabalham nestes serviços acabam tendo que lidar com a dor e o sofrimento alheio; o estresse quando as condições de trabalho não são favoráveis ao seu pleno desempenho; o cotidiano que exige conciliar a profissão pouco reconhecida e mal remunerada com a própria manutenção do seu emprego e a de seus dependentes. ${ }^{9}$

A precarização do trabalho do enfermeiro faz, geralmente, com que esse trabalhador sinta a necessidade de aumentar sua jornada de trabalho diária, através de horas extras, ou mesmo possuindo mais de um vínculo empregatício. Uma das formas adotadas pelos trabalhadores para complementação de sua renda é o aumento da jornada de trabalho ${ }^{10}$, com turnos de 12 até 24 horas e, por vezes, possuir outro vínculo empregatício. entrevistados:

Esta dupla jornada favorece o desgaste. ${ }^{10}$ Isso pode ser refletido na fala de um dos

O fato de ter mais de um vínculo influencia demais! Porque você não é máquina! Você sai cansado de um trabalho já para o outro, certo?! (E5)

Identificam-se assim, as cargas fisiológicas que são derivadas, fundamentalmente, das diversas maneiras de trabalhar. E estão constituídas, dentre outros elementos, pelas horas extras de trabalho e pelo prolongamento da jornada laboral. ${ }^{8}$

Se a gente ganhasse o suficiente para ter um só vínculo [...]. Hoje qualquer pessoa da saúde, é muito difícil ter só um vínculo. Lógico, se você trabalha $40 \mathrm{~h}$ semanais você teria mais folgas para ter mais lazer. [...] Mas, você fica praticamente só para isso, porque você passa a ter dois vínculos. (E3)

Segundo os entrevistados, o baixo salário condiciona a dupla e, as vezes, a tripla jornada de trabalho. Assim, essas longas jornadas de trabalho, os turnos desgastantes, a multiplicidade de funções, o ritmo excessivo de trabalho, a ansiedade, os esforços físicos, as posições incômodas, a separação do trabalho intelectual e manual e o controle das chefias, desencadeiam acidentes e doenças relacionadas ao trabalho. ${ }^{10}$

Tudo isso passa a gerar no trabalhador um resultado negativo, que pode ser reflexo de acidentes frequentes, doenças relacionadas ao trabalho tais como: dores lombares, estresse, irritabilidade, desânimo, causando o desinteresse ou abandono da profissão. ${ }^{11}$

Ainda são mencionados como consequências das condições de trabalho, os conflitos interpessoais; a ausência de articulação da equipe; condições estas que podem ser uma fonte potencial de estresses.

Essa precariedade nas condições de trabalho, somadas às dificuldades de convivência com os colegas de profissão, acarreta prejuízos na vida privada desses trabalhadores. Com isso, sacrificam o tempo dedicado à convivência familiar em função de mais tempo dedicado ao trabalho, o que pode gerar um sentimento de vazio e fragilização dos laços afetivos. ${ }^{12}$ 


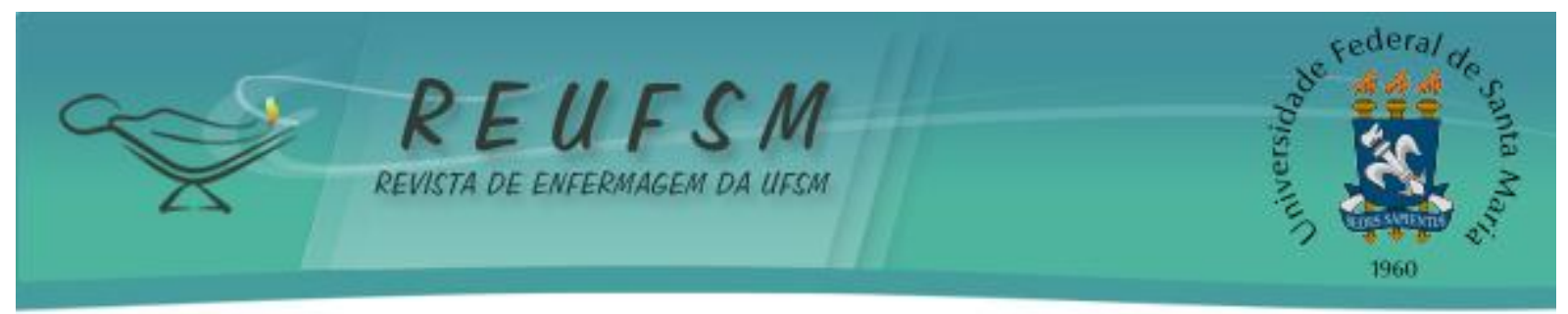

Foi citado ainda enquanto condição de desgaste, o cenário do trabalho, ou seja, a via pública. Esse ambiente possibilita o contato direto com situações de dor para o paciente e para os familiares, que estão naquele momento presenciando a atuação dos profissionais. Assim, por vezes, os familiares e a população em geral, por não compreenderem o momento, e as ações desempenhadas, acabam exigindo desses profissionais mais do que realmente pode ser feito. ${ }^{13}$

\section{Desgaste do corpo físico e da mente}

Outro núcleo de sentido construído foi o próprio desgaste físico e mental decorrente de situações como o desequilíbrio sono-vigília, do receio do inesperado e do receio em ocorrer acidentes de trabalho. Foi citado pelos entrevistados o temor de sofrer acidentes de trabalho. Estes são conceituados como aqueles ocorridos no exercício do trabalho a serviço da empresa ou pela atuação com os segurados especiais e que provoquem lesão corporal ou perturbação funcional, que cause morte, perda ou redução, permanente ou temporária, da capacidade para o trabalho. ${ }^{14}$

Tenho medo de um acidente no próprio atendimento ou de um acidente de trabalho com a própria viatura [...] o risco de você ter um acidente com perfurocortante. (E6)

Além dos acidentes de trabalho decorrentes do trajeto na viatura do SAMU, existe a possibilidade de acidentes com material perfurocortante e de exposição ao material biológico como o sangue dos pacientes, por exemplo. Tratam-se das cargas orgânicas que são derivadas principalmente do objeto de trabalho, e das condições de higiene ambiental em que ocorre sua transformação.

Neste grupo está incluído qualquer organismo animal ou vegetal, que possa determinar danos à saúde do trabalhador, como, por exemplo, bactérias, fungos, vírus e parasitas. No préhospitalar esta situação possui um agravante a mais, que é o fato de se trabalhar na urgência móvel, onde o veículo da equipe acaba se submetendo a velocidades extremas.

Um estudo sobre o atendimento pré-hospitalar e seus fatores de riscos ocupacionais, concluiu que o risco de acidente aparece como mais elevado, devido ao cenário em que os profissionais estão inseridos, diferenciando-se do sistema hospitalar, onde a estrutura e os processos podem ser adequados à prevenção de acidentes. ${ }^{15}$

\section{CONCLUSÃO}

Com a realização desse estudo podemos perceber que, para os enfermeiros de Pré-Hospitalar, o conceito de desgaste está intrinsecamente relacionado às características do serviço; ausência de boas condições laborais que ofereçam suporte ao trabalhador, bem como o risco para a vida profissional acarretando o desgaste do corpo e da mente. Desse modo, pode-se dizer que os enfermeiros de Atendimento Pré-Hospitalar Móvel convivem com o estresse no ambiente de trabalho como uma característica inerente ao trabalho da urgência e emergência. Assim, o estresse passa a ser naturalizado, tornando-se desgastante para o trabalhador que o vivencia diariamente mesmo sem perceber. Além disso, foi citado como contribuintes ao desgaste desse profissional as condições em que o trabalho é desempenhado, bem como a jornada de trabalho prolongada e as características próprias de se trabalhar em pré-hospitalar móvel.

Outro ponto importante a destacar é que a partir do momento que esses profissionais tomam consciência da presença de desgaste em seu corpo relacionado ao 


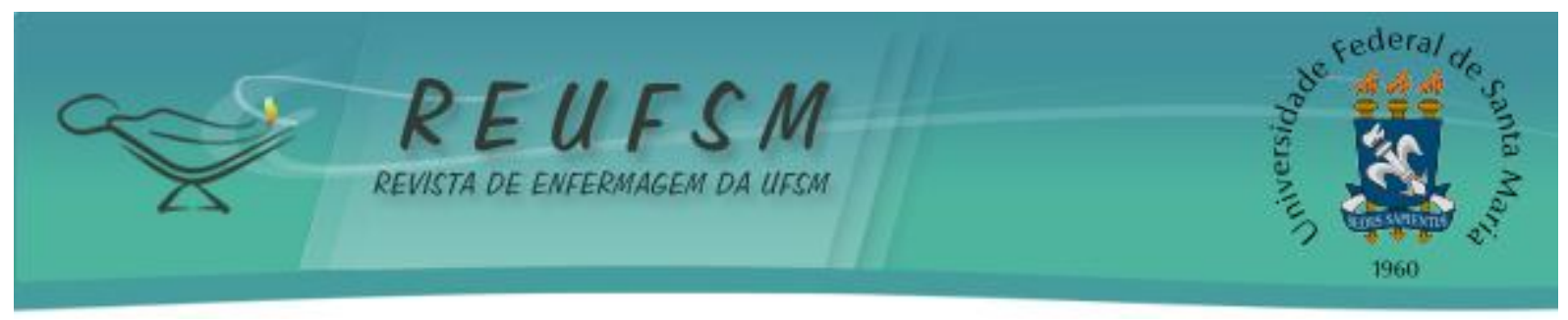

trabalho eles são capazes de pensarem e desenvolverem estratégias para amenizar tal situação por eles enfrentada, seja como fuga do local de trabalho e busca por situações prazerosas ou mesmo diminuindo sua carga horária em razão de sua saúde. ${ }^{16}$

Vale salientar que este estudo foi realizado com uma população de sete enfermeiros do SAMU-Mossoró, constituindo-se uma realidade única vivenciada, constituindo-se a limitação do estudo. Com isso, pode apresentar aproximações ou distanciamentos de outras realidades, reforçando a necessidade de novos estudos que possam retratar essa temática.

Quanto às contribuições do estudo para o serviço, destacamos o fato de proporcionar a esses enfermeiros uma maior reflexão sobre o cuidar de si no ambiente de trabalho a fim de evitar danos maiores causados por este.

\section{REFERÊNCIAS}

1. Nunes ED. Medicina social: aspectos históricos e teóricos. São Paulo: Global; 1983.

2. Rigotto RM. Desenvolvimento, ambiente e saúde - implicações da (des)localização industrial. Rio de Janeiro: Fiocruz; 2008.

3. Dias LG, Nogueira MM, Dutra GO, Souza BM, Ávila LC. Caracterização e formas de enfrentamento do estresse no profissional de enfermagem de atendimento pré-hospitalar. Rev Pesq Cuid Fundam [internet]. 2011 [acesso em $2011 \mathrm{dez}$ 13];3(2):1943-58. Disponível em: http://www.seer.unirio.br/index.php/cuidadofundamental/article/view/1047/pdf_355.

4. Ministério da Saúde (BR). Lista de doenças relacionadas ao trabalho. Brasília (DF); 2004.

5. Ministério da Saúde (BR). Política nacional de atenção às urgências. Brasília (DF); 2004.

6. Minayo MCS. O desafio do conhecimento: pesquisa qualitativa em enfermagem. São Paulo: Huccitec; 2008.

7. Orlandi EP. Análise do discurso: princípios \& procedimentos. Campinas (SP): Pontes; 2005.

8. Rocha LE, Rigotto RM, Buschinelli JTP. Isto é trabalho de gente? vida, doença e trabalho no Brasil. São Paulo: Vozes; 1993.

9. Veras VSD. Aumento da jornada de trabalho: qual a repercussão na vida dos trabalhadores de enfermagem? [dissertação]. 121f. Natal, RN: Universidade Federal do Rio Grande do Norte; 2003.

10. Rocha MCP. Estresse e o ciclo virgília-sono do enfermeiro que atua em diferentes setores do ambiente hospitalar [dissertação]. 215f. São Paulo: Universidade Estadual de Campinas; 2008.

11. Silva RM da, Beck CLC, Magnago TSBS, Carmagnani MIS, Tavares JP, Prestes FC. Trabalho noturno e suas repercussões na saúde dos enfermeiros. Esc Anna Nery Rev Enferm [internet]. 2010 [acesso em 2011 dez 15];15(2):270-6. Disponível em: http://www.scielo.br/pdf/ean/v15n2/v15n2a08.pdf.

12. Oliveira EB, Lisboa MTL, Aliprandi LV, Sisnando SD. A inserção do acadêmico de enfermagem em uma unidade de emergência: a psicodinâmica do trabalho. Rev Enferm UERJ [internet]. 2004 [acesso em 03 de dez 2011];12:179-85. Disponível em: http://www.facenf.uerj.br/v12n2/v12n2a09.pdf.

13. Garlet ER. O processo de trabalho da equipe de saúde de uma unidade de atendimento às urgências e emergências [dissertação]. 96f. Porto Alegre (RS): Universidade Federal do Rio Grande do Sul; 2008. 


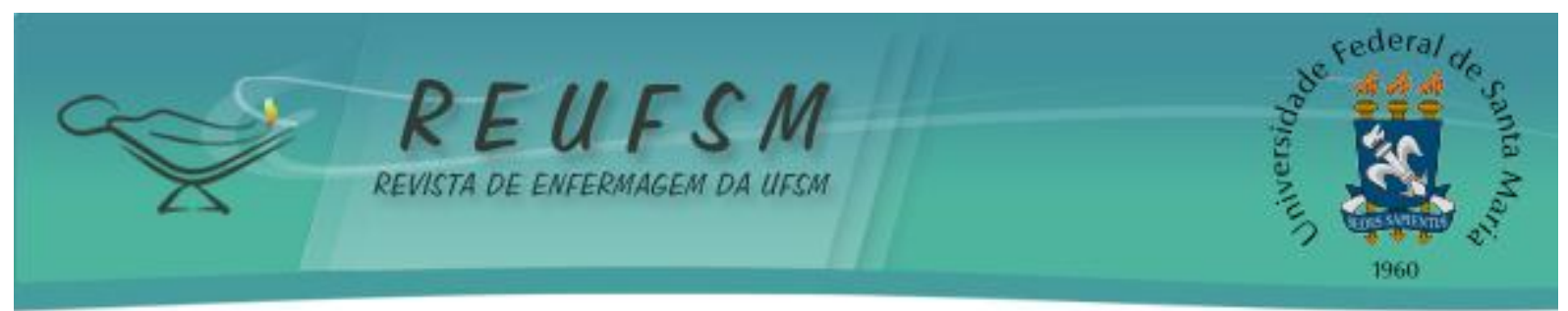

14. Ministério da Saúde (BR). Organização Pan-Americana da Saúde no Brasil. Doenças relacionadas ao trabalho: manual de procedimentos para os serviços de saúde. Brasília (DF); 2001.

15. Secco IAO. Acidentes e cargas de trabalho dos trabalhadores de enfermagem de um hospital universitário do norte do Paraná [tese]. 291f. São Paulo: Universidade de São Paulo; 2006.

16. Silva AA, Terra MG. O cuidado de si do/da profissional de enfermagem em saúde mental. Rev Enferm UFSM [internet]. 2011 [acesso em 2012 mar 25];1(3): 514-5. Disponível em: http://cascavel.ufsm.br/revistas/ojs-2.2.2/index.php/reufsm/article/view/3566/2402.

Data de recebimento: $08 / 02 / 2012$

Data de aceite: 08/06/2012

Contato com autor responsável: Cláudia Cristiane Filgueira Martins

Endereço: Rua Sebastião Barreto, 91, bl 12, apt 202, Bairro Neópolis. Natal,RN

Cep: 59080-480

E-mail: claudiacrisfm@yahoo.com.br 